\title{
Climate control in vacuum dryers for convective heat transfer
}

\section{Part 2: Actual climates in industrial kilns and suggestions to improve kiln design}

Björn A. Källander

\begin{abstract}
The first part of this contribution determined the demands on climate control in vacuum drying kilns that are necessary to achieve the final moisture content variation stipulated in the European Drying Group (EDG) proposal on wood drying quality standards. In this second part of the contribution, these demands are compared with measurements of actual climates and the resulting final moisture content in vacuum kilns during industrial production. The measurements show that none of the studied industrial vacuum kilns are capable of controlling climate with acceptable accuracy. The variations in drying climate lead to large variations in final moisture content and reduced production capacities. Drying quality and drying capacity would be greatly increased with improved kiln design and improved climate control systems. Critical factors in kiln design and climate control system design necessary to maintain a controlled drying climate are listed.
\end{abstract}

\section{Demands on temperature and pressure control}

In the previous part of this contribution (Källander 2002) it was shown that the crucial factor in climate control is maintaining the set temperature. With a pressure control system capable of maintaining the pressure within $\pm 0.1 \%$ of the set pressure, the temperature has to be maintained within $\pm 0.8^{\circ} \mathrm{C}$ of the set temperature throughout the kiln to achieve the top drying class known as "Exclusive". The demands on temperature control to reach different drying classes are shown in Table 1.

Received: 20 April 2000

Published online: 11 April 2003

(C) Springer-Verlag 2003

B.A. Källander $(\bowtie)$

Stora Corporate Research AB, 79180 Falun, Sweden

E-mail: bjorn.kallander@sp.se

B.A. Källander

Building Material, Royal Institute of Technology,

10044 Stockholm, Sweden

Present Address: B.A. Källander

SP Swedish National Testing and Research Institute, Box 857,

50115 Borås, Sweden 
Table 1. Demands on temperature control to reach EDG- Drying classes S, Q and E if the pressure is maintained within $\pm 1 \%$ of set pressure

\begin{tabular}{lll}
\hline $\begin{array}{l}\text { EDG drying } \\
\text { class }\end{array}$ & $\begin{array}{l}\text { Allowable MC } \\
\text { variation } 90 \% \text { of } \\
\text { all pieces within }\end{array}$ & $\begin{array}{l}\text { Temperature should } \\
\text { be kept within }\end{array}$ \\
\hline
\end{tabular}

Standard (S)

Quality (Q)

Exclusive (E)

$$
\begin{aligned}
& \pm 0.3 * \text { MC target } \\
& \pm 0.2 * \text { MC target } \\
& \pm 0.1 * \text { MC target }
\end{aligned}
$$

$\pm 2.5^{\circ} \mathrm{C}$ of set temperature

$\pm 1.7^{\circ} \mathrm{C}$ of set temperature

$\pm 0.8^{\circ} \mathrm{C}$ of set temperature

\section{Measurements of actual climates in vacuum kilns}

Studies of the drying climate in industrial vacuum kilns have shown systematic variations in the kiln drying climate that greatly exceed the acceptable levels calculated above (Hedlund 1996). The systematic variations in drying climate can be divided into three main categories:

1. Systematic variations of temperature between different parts of the kiln

2. Irregular steam flow patterns resulting in some volumes in the wood batch with high steam flow and some volumes with very low steam flow

3. Incapability of the climate control system to maintain the desired set temperature at the control points.

The problems are clearly illustrated by measurements in industrial vacuum kilns, as shown below.

\section{Systematic temperature variations}

Until recently, vacuum kilns have been designed with a single climate control zone along the entire length of the kiln. This feature makes it impossible to counteract differences in heat losses along the kiln or variations in drying characteristics of the wood. The temperature will be lower at the ends of the kiln, where heat losses are greater compared to more central parts of the kiln, resulting in higher final moisture content (MC). Measurements in a vacuum kiln drying oak showed approximately $3^{\circ} \mathrm{C}$ lower temperatures at the kiln ends in the later drying stages, resulting in an average final $\mathrm{MC}$ of $7.2 \%$ in these areas, while the centre sections had an average final MC of 6.6\% (Hedlund 1996).

The systematic temperature variations along the kiln can be greatly accentuated if the kilns are loaded with wood with mixed drying characteristics, such as varying thickness. Temperature differences along the kiln exceeding $29^{\circ} \mathrm{C}$ have been recorded in a 24-m-long kiln loaded with beech of thickness between $19 \mathrm{~mm}$ and $38 \mathrm{~mm}$ (Hedlund 1996).

As few vacuum kilns reverse steam flow, they will show a systematically higher temperature on the pressure side in comparison to the suction side of the stack, resulting in lower final MC on the pressure side. Measurements in a vacuum kiln with fans above the stack and a $2.1 \mathrm{~m}$ stack width showed an average temperature drop across the stack of $1.2^{\circ} \mathrm{C}$ with resulting average final $\mathrm{MC}$ of $6.7 \%$ on the pressure side as compared to $6.9 \%$ on the suction side (Hedlund 1996).

Vacuum kilns commonly show lower temperatures in the lower parts of the stack in comparison to higher parts, resulting in higher final MC in the bottom part of the stack (Hedlund 1996). The reasons for this varies from an uncontrolled cooling effect, probably caused by heat flux through the loading cart (Hedlund 
1996), to kiln designs where the bottom of the kiln is deliberately cooled to condense steam as in early Brunner- Hildebrand vacuum kilns.

\section{Irregular steam flow patterns}

The high investment cost of vacuum autoclaves has created a trend to maximise the batch volume of kilns, with designs placing the fans either beside the wood stack or at the ends of the kilns (Fig. 1).

Several studies have shown irregular steam flow patterns and resulting uncontrolled drying quality in vacuum kilns with fans placed beside the stack (Weber 1991; Trübswetter, personal communication, 1994; Longauer and Trebula 1995; Hedlund 1996) and in kilns with fans placed at the kiln end (Ledig and Militzer 1999). The steam will flow by the easiest route from the pressure side of the fans to the suction side, resulting in very high velocities close to the fans and virtually no steam flow in areas far from the fans (Fig. 2).

Irregular steam flow patterns cause the wood to be dried in an uncontrolled sequence. The wood in areas of low steam velocity or cold volumes of the stack is not dried until the wood "upwind" has reached the EMC. This leads to longer drying times than would normally be necessary to reach an acceptable MC variation, if it is possible to reach the low MC variation at all. Uncontrolled steam flow patterns can also be expected to increase drying defects caused by the uncontrolled climate variations in the kiln. Kilns with fans placed above the wood also show systematic, however less severe, variations in the temperature distribution and the final MC distribution between the top and bottom of the stack. Measurements in industrial vacuum kilns with fans above the wood stack have indicated lower final MC than the kiln average in the lower half of the stack on the pressure side and the upper half of the suction side.

Vacuum kilns with fans placed beside the wood stack as well as kilns with fans above the wood stack regularly show large steam volumes passing around the stack at the ends of the kiln instead of passing through the stack. The slower drying rates caused by lower temperatures at the ends of the kiln can thus be expected to be accentuated by lower steam velocities through the stack at the ends of the kiln (Hedlund 1996). One method to reduce this effect is to install inner doors or plates at the end of the wood stack, cutting off the ends of the kiln from the steam flow. These plates function both as baffles, forcing the steam through the stack, and as a barrier, creating an isolated chamber and reducing heat loss through the kiln ends.

\section{Temperature fluctuations}

As the amount of heat energy stored in the water or oil in the heat coils is large compared to the total mass of the steam, a crude temperature control system will

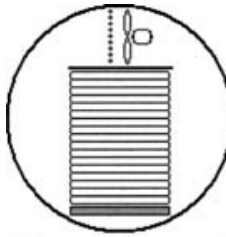

Fans above wood stack

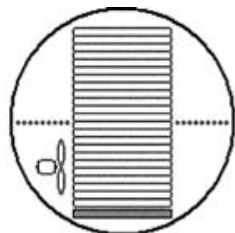

Fans beside wood stack

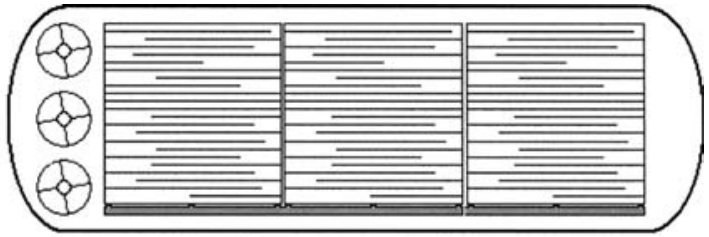

Fans at end of kiln

Fig. 1. Common fan configurations in vacuum kilns 


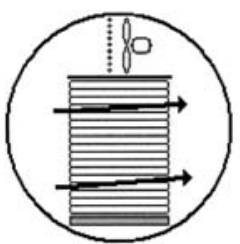

Fans above wood, possible to control steam flow.

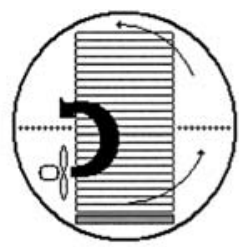

Fans beside wood, high steam velocity close to fans and very low in other areas.

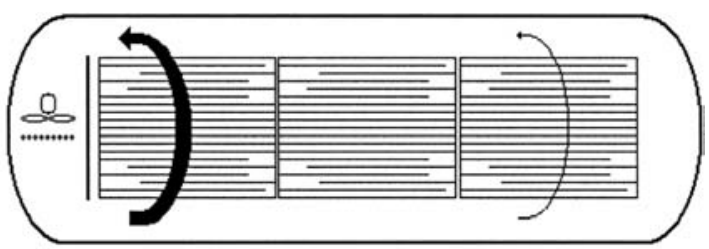

Fans at end of kiln, high steam velocity close to fans and low steam velocity farther away from fans.

Fig. 2. Expected steam flow patterns in kilns with different fan configurations

cause large uncontrolled variations of the steam temperature. Large variations in drying temperature can be seen in vacuum kilns with on/off regulation of heat valves, especially at the end of the drying process when the power demand is limited (Behnke et al. 1995; Hedlund 1996). The oscillations of the drying climate can be increased by variations in pressure due to on/off regulation of the vacuum pump. Several vacuum kiln designs use climate control systems based on set temperature and set $\mathrm{RH}$ - values rather than set temperatures and set pressures. The connection between pressure, temperature and $\mathrm{RH}$ in combination with long response times of the temperature and pressure control systems, can lead to an increase in both the amplitude and the time period of the oscillations, creating a risk of wood damage. Time periods exceeding $2.5 \mathrm{~h}$ and amplitudes exceeding $5^{\circ} \mathrm{C}$ can be seen at the final stages of the drying process (Hedlund 1996).

A common problem in vacuum kilns is an uncontrolled temperature increase in the later stages of the drying process caused by the energy released from the fan motors as the power demand of the drying process is reduced. Measurements have shown temperatures increasing up to $10^{\circ} \mathrm{C}$ above the set temperature (Hedlund 1996).

\section{Critical design factors to reach a controlled drying climate}

The design of a vacuum kiln should incorporate two main features in order to reach a controlled drying process:
A. A capability to reach and maintain the set climate at the control points throughout the drying process
B. To ensure a controlled steam flow pattern.

In addition to maintaining the set climate, a vacuum kiln should have a conditioning system capable of remoistening the wood in order to reduce the MC gradient of the wood.

\section{Maintaining the set climate}

As the drying climate is defined by pressure and temperature, both are equally important to control. However, as opposed to temperature, pressure will always be more or less equal throughout the entire length of the kiln and varies only by the fan pressure. This makes it advantageous to base the climate control system on a well-defined pressure and thus the vacuum pump should be equipped with a proportional/integrating/derivating (PID) or PI control system. 
When the pressure is defined, climate control can be based on temperature control.

The temperature control system must be divided into individually controlled climatic zones along the kiln in order to maintain the set temperature along the entire length of the kiln. Variations in heat losses through the kiln walls as well as variations in drying characteristics of the wood can only be controlled by using climate control zones.

The number of zones depends on the dryer length and the expected variations in drying characteristics of the wood to be dried. A minimum of three zones is needed to allow for one zone in the centre section and one zone at each end of the kiln. Each climate control zone needs to incorporate individual temperature measurements and individually controlled heating coils.

As the energy demand is greatly reduced at the end of the drying process, a simple on/off regulation of the heat valves is insufficient. The heat valves of each climate control zone should be equipped with a PI or PID control system. The energy input from the fan motors can cause an uncontrolled temperature increase at the end of the drying process so it is necessary either to cool the steam or to reduce the fan speed. The kiln and the wood cart should be designed to reduce the risk of a cooler drying climate at the bottom of the stack. This could be achieved by means of an insulated cart bottom or double bottom plates where a limited amount of steam is allowed to pass below the stack in order to heat the cart.

\section{Controlled steam flow pattern}

The only possible method to ensure a controlled steam flow pattern is to have a well-defined pressure side and suction side of the stack. The steam must pass from one side of the stack to the other. In a very short kiln this can be achieved with the fans placed at the ends of the stack, but in a kiln of normal industrial size, the fans should be placed above the stack. A fan configuration with the fans beside the wood stack will always result in an uncontrolled drying process, since the steam will follow the easiest route from the pressure side to the suction side of the fans, resulting in dry areas and wet areas of the cross section.

The steam should pass through the wood stack with a well-defined velocity. Thus no steam should be allowed to pass around the stack at the ends, above or below. This makes it necessary to use flaps above the stack and at the stack ends. Weights, in the form of plates resting on the stack, have the double advantage that they eliminate the risk of steam passing above the stack and reduce deformations of the wood. In a similar fashion, plates at the ends of the stack eliminate the risk of steam passing around the stack, reduce end checking, and reduce the risk of colder steam at the ends due to the relatively greater heat losses through the kiln ends. The direction of steam flow should be reversed as in conventional kilns in order to reduce the effect of the temperature drop across the stack.

\section{Conditioning system}

In order to accomplish an efficient conditioning phase it is necessary to add moisture to the wood. It is of vital importance, therefore, to incorporate a water spray or steaming system to the kiln design. Such a system also benefits the initial heating phase. Steaming systems are incorporated in, for instance, BrunnerHildebrand and Maspell vacuum kilns (Ressel 1993) and water spray systems in 
Vanicek (Vanicek and Bittner 1992) and Mühlböck vacuum kilns (Mühlböck, personal communication, 1993). The suggestions above are presented in Fig. 3.

\section{Discussion}

The demands on temperature control in vacuum kilns in order to fulfil the demands of the EDG Exclusive class are close to the theoretical limits of an industrial drying kiln. The only possible method to maintain the temperature throughout an industrial kiln with sufficient accuracy is to use independent climate control zones equipped with a PI or PID control system. Furthermore, it is only possible to create a predictable temperature profile across the wood batch if the steam flow is well defined. This is impossible without a well-defined pressure side and suction side of the batch meaning it is necessary to place the fans above the wood in large industrial kilns. None of the industrial kilns in which measurements were made can control the climate with acceptable accuracy to reach the EDG Exclusive drying class except at very low target MC levels.

\section{Conclusions}

The temperature control system should be divided into independent zones along the kiln in order to maintain the set climate and the heat valves of each climate control zone should be controlled by a PI or PID regulation system.

Steam flow patterns must be well defined in order to reach a controlled drying process. Fans should be placed above the wood in order to accomplish such controlled steam flow, with the possible exception of very short kilns. The fans should be reversed at regular intervals and be equipped with speed control.

The vacuum pump should be equipped with a PI-regulation system or equivalent. The kiln should be equipped with a conditioning system with the ability to add moisture to the wood. With proper climate control, the final drying quality will be improved since the drying schedule can be controlled, making it possible to dry wood to higher final MC as the MC variation will be reduced.

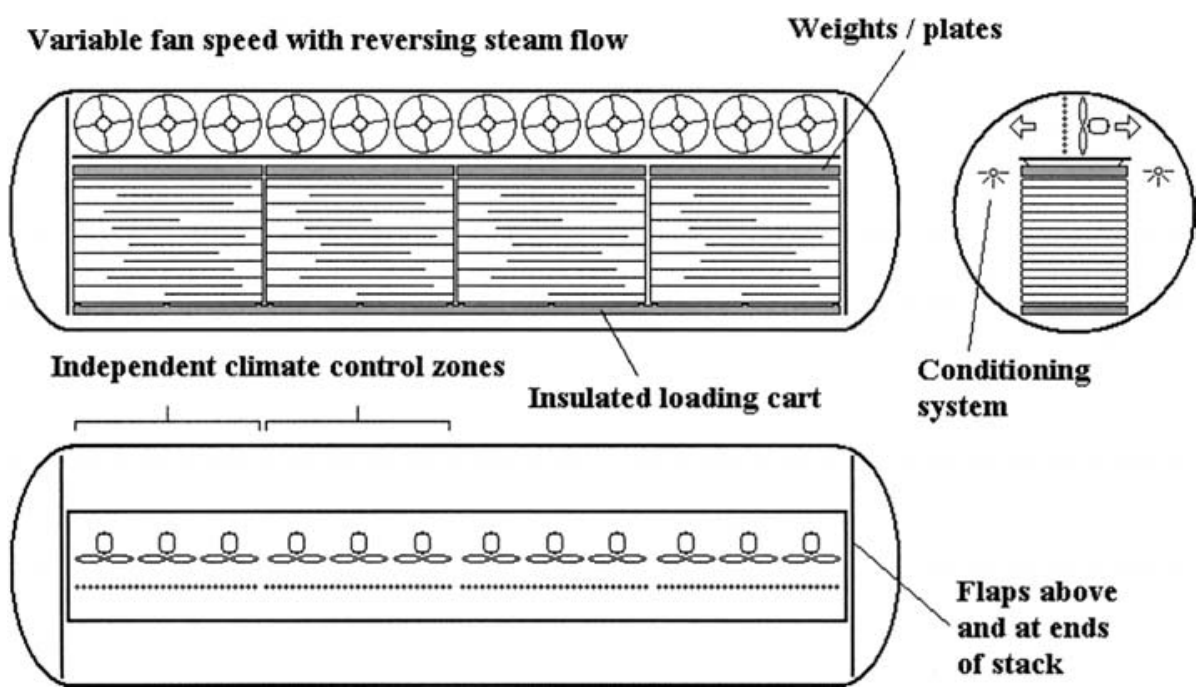

Fig. 3. Suggestions to reach a controlled drying climate in a vacuum kiln 


\section{Future work}

Vacuum drying with convective heating can also be described as drying in superheated steam at reduced pressure. A study of climate variations in an industrial kiln working with superheated steam at atmospheric pressure is being prepared. In addition, the knowledge of steam flow patterns during drying within vacuum kilns is limited; further measurements are needed.

This article is based on the assumption that the final MC can be controlled by means of the short term average EMC of the climate surrounding the wood. It is possible that the drying process could be better described by means of an energy transfer model, but we lack working theoretical models for wood drying in superheated steam and such studies are encouraged.

\section{References}

Behnke C, Kovácik I, Militzer KE (1995) Monitoring the drying process in vacuum kiln. Proceedings, Vacuum drying of wood, High Tatras, Slovak Republic, 8-12 October 1996

Hedlund B (1996) Temperature and final MC distributions in vacuum dryers with different fan configurations. Proceedings, 5th International IUFRO Wood drying conference, Québec City, Canada, 13-17 August 1996

BA Källander (2002) Climate control in vacuum dryers for convective heat transfer. Part 1: Demands on climate control. Wood Sci Technol 36(6):477-486

Ledig SF, Militzer KE (1999) Measured gas velocity and moisture content distribution in a convective vacuum kiln. Proceedings, 6th International IUFRO Wood drying conference. Stellenbosch University, Matieland, South Africa, 25-28 January 1999

Longauer J, Trebula P (1995) Influence of circulation intensity on homogenity of wood drying monitored at outlet of stack. Proceedings, Vacuum drying of wood, High Tatras, Slovak Republic, 8-12 October 1996

Ressel JB (1993) Zum aktuellen Stand der Vakuumtrocknung von Schnittholz. Part 2: Beschreibung der auf der Messe vorgestellten Anlagen. Holz Zentralblatt 79:1313-1315

Vanicek T, Bittner T (1992) Technology of vacuum kilns. Proceedings, 3rd IUFRO International Wood Drying Conference, Vienna, Austria, 18-21 August 1992

Weber M (1991) Untersuchungen über das Verfahren der Unterdrucktrocknung nach Moldrup. Diplomarbeit, Fachhochschule Rosenheim. Rosenheim, Germany 